\title{
Noncompliance to Diet and Medication among Patients with Type 2 Diabetes Mellitus in Selected Hospitals of Kathmandu, Nepal
}

\author{
${ }^{1}$ Department of Public Health, Tribhuvan University Institute of \\ Medicine, Kathmandu, Nepal \\ 2Department of Internal Medicine, Northside Medical Center, \\ Youngstown, Ohio, United States
}

Nisha Kusum Kafle ${ }^{1} \quad$ Resham Raj Poudel ${ }^{2} \quad$ Sushan Man Shrestha ${ }^{1}$

\begin{abstract}
Address for correspondence Nisha Kusum Kafle, BPH, Department of Public Health, Tribhuvan University Institute of Medicine, Kathmandu, Nepal (e-mail: kusumkafle27@gmail.com).
\end{abstract}

J Soc Health Diab 2018;6:90-95.

\begin{abstract}
Background Diabetes is a major public health problem affecting people of all ages globally. Noncompliance compromises the effectiveness of treatment and adversely affects patients' health. The main purpose of this study was to assess and compare the proportion of noncompliance to diet and medication between patients with type 2 diabetes mellitus (T2DM) visiting public and private hospitals in Kathmandu, Nepal. Methods Descriptive cross-sectional study was conducted in T2DM patients visiting public and private hospitals. Eight item Morisky Medication Adherence Questionnaire (MMAQ) for medication adherence and Perceived Dietary Adherence Questionnaire (PDAQ) for dietary adherence were used. Epidata was used for data entry and SPSS for data analysis. Chi-square test was used as a test of significance. Odds ratio (OR) and the corresponding $95 \%$ confidence intervals $(\mathrm{Cl})$ were calculated.

Results The study involved 182 T2DM patients. Participants' age was $\geq 17$ years and they were under treatment for $\geq 6$ months. Mean age of the participants was 54.67 years with standard deviation $(S D) \pm 11.69$. Prevalence of medication noncompliance was seen in 126 (69.2\%) patients, whereas prevalence of dietary noncompliance was seen in $166(91.2 \%)$ patients. Illiterate participants were more likely to be noncompliant than literate to medication (OR 4.32, $p=0.001$ ). Self-employed were more likely to be noncompliant to medication than job holders (OR 2.93, $p=0.008$ ). People visiting public hospital were more likely to be noncompliant to diet than those visiting private hospital (OR 4.89, $p=0.009$ ). Illiterate participants were more likely to be noncompliant to diet than literate (OR 10.94, $p=0.005)$.

Keywords

- diet

- medication

- noncompliance

- type 2 diabetes mellitus

Conclusion The T2DM patients visiting public hospitals were more noncompliant to diet. Illiterate patients were more noncompliant to both medication and diet. Self-employed compared with job holders were more noncompliant to medication. Patient education and counseling should be aggressively addressed mainly in public hospitals. There was no significant difference in medication noncompliance between public and private hospitals $(p=0.108)$.
\end{abstract}

\section{Introduction}

Diabetes is a group of metabolic disorders associated with long-term damage, dysfunction, and failure of different organs, especially the eyes, kidneys, nerves, heart, and blood vessels. ${ }^{1}$ Majority (90-95\%) of patients have type 2 diabetes mellitus (T2DM). ${ }^{2}$ Compliance to diet and medication is defined as an extent to which a person's behavior in terms 
of taking medications and following diet coincides with the health care provider's recommendations. ${ }^{3}$

According to the World Health Organization (WHO), diabetes is the sixth leading cause of death accounting for 1.59 million deaths in 2015. ${ }^{4}$ According to International Diabetes Federation (IDF), diabetes affects approximately 415 million people worldwide, and the number is expected to reach 642 million by 2040 with two-thirds of all diabetes cases and > $75 \%$ of diabetes deaths occurring in low- to middle-income countries. ${ }^{5}$ According to the IDF data for Nepal, prevalence of T2DM in 20 to 79 years age group was $4 \%$ in 2017, and the predicted number of undiagnosed cases was 532,100. IDF estimates the prevalence to reach $6.1 \%$ and $1,264,200$ undiagnosed cases in 2045. ${ }^{6}$ Diabetes is the third most common noncommunicable disease in Nepal, which causes $12 \%$ of all hospitalizations. ${ }^{7}$ T2DM is emerging as a major health care problem in Nepal, with rising prevalence and its complications, especially in urban population complicated by noncompliance of diet and medication ${ }^{8}$ Centralized health care, poor referrals and consultation system, and increasing trends of urban lifestyle in Nepal further complicate diabetes management ${ }^{9}$ In a cross-sectional study in Nepal, dietary noncompliance was $87.5 \%$ and $12.5 \%$ were poorly compliant. ${ }^{10}$ In another study, only one-fifth of the patients believed that being compliant to dietary advice helps reduce blood glucose. ${ }^{11}$ Diabetes is a chronic disease that requires lifelong treatment. It greatly increases the risk of serious, long-term complications and affects health care costs and overall quality of life. Noncompliance to long-term therapy severely compromises the effectiveness of treatment and adversely affects the patient's condition. ${ }^{12}$ Compliance to medication and dietary recommendations lessens the disease burden by reducing morbidity, mortality, and complications associated with T2DM. ${ }^{13}$

\section{Methods}

Between August 2017 and October 2017, a descriptive, analytical study with cross-sectional design was performed at four hospitals in Kathmandu, Nepal: two tertiary care public hospitals (TU Teaching Hospital and Bir Hospital) and two private hospitals (Metro Hospital and Diabetes Thyroid \& Endocrinology Care Center). Hospitals were selected keeping in mind to cover the most representative population. The study population included all registered T2DM patients attending outpatient departments of selected hospitals during research period. All participants were of age $\geq 17$ years and were under treatment for at least 6 months. Patients with gestational diabetes, severe comorbidity, and severe mental illness were excluded.

The minimum required sample size was calculated as 182 by using the formula $n=z^{2} p q / d^{2}$, where $n=$ required sample size, $p=$ prevalence of noncompliance to diet, which was $87.5 \%$ [10], $q=1-p$ and $d=$ deviation of $\pm 5 \%$ from true prevalence, and $z=$ level of confidence measured; for 95\% confidence interval (CI) $(\alpha=0.05), z=1.96$. The study tool was pretested in 15 patients ( $8 \%$ of sample size) at Sahid Gangalal National Heart Center, Kathmandu. Necessary corrections and adjustments were made, and tools were finalized. Responses from pretest were not included in final analysis. Equal number of sample from each hospital was taken, that is, 46 samples from each four hospital. Because of limited time, resources purposive sampling was used for selecting samples. Data were collected by face-to-face interview with the patient by the researcher, after taking informed written consent.

Morisky Medication Adherence Questionnaire (MMAQ) that is a validated questionnaire was used to assess medication noncompliance. ${ }^{14,15} \mathrm{MMAQ}$ consists of eight questions in which questions 1 to 7 have response choice Yes or No and question 8 has 5 -point Likert response choice. Based on score obtained, 8 was considered as high compliance, 6 and 7 as medium compliance, and $<6$ was considered as low compliance.

Dietary noncompliance was assessed by using validated questionnaire Perceived Dietary Adherence Questionnaire (PDAQ). ${ }^{16}$ PDAQ is a 7-point Likert scale-based tool to measure dietary compliance. It has a total of nine questions, with scores ranging from lowest 0 to highest 7. Total score of PDAQ is 63 . Based on the score obtained, $>75 \%$ was considered as high compliance, 50 to $75 \%$ as medium compliance, and $<50 \%$ as low compliance. Sociodemographic, behavioral, and other related variables used were based on previous studies and WHO NCD STEPS instrument. ${ }^{17}$ For statistical analysis of both medication and diet noncompliance, only high compliance was considered as true compliance, and middle and low compliance were considered as noncompliance.

After coding, editing, and cross-checking, data were entered in EpiData ver. 3.1 (The EpiData Association Odense, Denmark 2004) and then exported to SPSS ver. 21 (IBM Corp: Armonk, NY, US 2012) for further analysis. Descriptive analysis was done in terms of number and percent for qualitative data, and mean and standard deviation (SD) for quantitative data. Bivariate analysis was performed to see the crude association of independent variable with the outcome variable by using chi-square test. $p$-Value $(<0.05)$ and $95 \% \mathrm{CI}$ were used to see the significance of association.

\section{Results}

Total 182 T2DM patients were interviewed. The mean age of participants was $54.67 \pm 11.69$ years, $53.3 \%$ were male, and $46.7 \%$ were female. Of total participants, $89 \%$ were married, $25.8 \%$ were illiterate, approximately $40 \%$ were household worker, and $32.4 \%$ were self-employed. Almost $85 \%$ of the participants were from city/municipality. Nearly $35 \%$ of participants had family history of diabetes. Mean duration of diabetes was $6.88 \pm 6.14$ years, $56 \%$ of participants had diabetes for $<5$ years, and remaining had diabetes for 5 to 28 years. More than one-half (62.5\%) of the participants had hypertension, and $38.46 \%$ had no additional disease besides T2DM. Of total, $14.1 \%$ of the participants were current smoker whereas $40.1 \%$ were ever smoker and $59.9 \%$ were never smoker. In case of drinking habit, $19.8 \%$ were current drinkers, $41.2 \%$ were ever drinkers, and $58.8 \%$ were never drinkers. Responses of the participants on MMAQ responses on PDAQ and the participants' noncompliance status are presented in - Tables 1 to 3, respectively. 
After considering only high compliance as compliance, and middle and low compliance as noncompliance: Prevalence of medication noncompliance, score $<8$ on MMAQ was $69.2 \%$. Prevalence of dietary noncompliance, score $<75 \%$ on PQDA was $91.2 \%$.

Chi-square test was used as a test of significance to see the association of independent variables (age, sex, marital status, health facility type, family history of diabetes, duration of diabetes, occupation, education, place of residence, smoking habit, and drinking habit) with outcome variable-noncompliance. Odds ratio (OR) and the corresponding 95\% CI were calculated, and two-sided $p$-value $<0.05$ was considered significant.

Factors found to be significantly associated with medication noncompliance on bivariate analysis were level of education and occupation of the participants. Illiterate (no formal education) participants were 4.32 times more likely to be noncompliant than literate (formal education) (CI: 2.00-9.30, $p=0.001$ ). Self-employed participants were 2.93 times more likely to be noncompliant than job holder (CI: $1.30-6.59, p=0.008)$.

Factors found to be significantly associated with dietary noncompliance on bivariate analysis were type of health

Table 1 Response on MMAQ-8

\begin{tabular}{|l|l|l|}
\hline \multirow{2}{*}{ Questions } & \multicolumn{2}{l|}{$\begin{array}{l}\text { Number (\%), } \\
n=182\end{array}$} \\
\cline { 2 - 3 } & Yes & No \\
\hline $\begin{array}{l}\text { Q1. Forget to take medicine } \\
\text { sometimes }\end{array}$ & $80(44)$ & $102(56)$ \\
\hline $\begin{array}{l}\text { Q2. Any days forgot to take } \\
\text { medicine over past 2 week }\end{array}$ & $\begin{array}{l}39 \\
(21.4)\end{array}$ & $\begin{array}{l}143 \\
(78.6)\end{array}$ \\
\hline $\begin{array}{l}\text { Q3. Stop taking medicine without } \\
\text { telling physician when felt worse }\end{array}$ & $20(11)$ & $162(89)$ \\
\hline $\begin{array}{l}\text { Q4. Sometimes forget to bring along } \\
\text { medicine when traveling or leaving } \\
\text { home }\end{array}$ & $\begin{array}{l}42 \\
(23.1)\end{array}$ & $\begin{array}{l}140 \\
(76.9)\end{array}$ \\
\hline $\begin{array}{l}\text { Q5. Took all medicines yesterday } \\
\text { Q6. Sometimes stop taking } \\
\text { medicines when symptoms are } \\
\text { under control }\end{array}$ & $\begin{array}{l}174 \\
(95.6)\end{array}$ & $8(4.4)$ \\
\hline $\begin{array}{l}\text { Q7. Ever feel hassled while sticking } \\
\text { to treatment plan }\end{array}$ & $\begin{array}{l}57 \\
(31.3)\end{array}$ & $\begin{array}{l}166 \\
(91.2)\end{array}$ \\
\hline $\begin{array}{l}\text { Q8. Difficulty in remembering to } \\
\text { take all your medicines }\end{array}$ & $\begin{array}{l}\text { Mean } \pm \\
\text { SD }\end{array}$ & $\begin{array}{l}0.89 \pm \\
0.23\end{array}$ \\
\hline
\end{tabular}

Abbreviations: MMAQ-8, Morisky Medication Adherence Questionnaire 8; SD, standard deviation. facility and level of education. Participants who visited public hospital were 4.89 times more likely to be noncompliant than those who visited private hospital (CI: 1.34-17.79, $p=0.009$ ). Illiterate participants were 10.94 times more likely to be noncompliant than literate participants (CI: 1.41-84.75, $p=0.005$ ). Characteristics of study participants are shown in - Table 4. Comparison of medication and diet noncompliance is shown in - Fig. 1.

\section{Discussion}

This is the first study conducted to see medication noncompliance in Nepal, whereas few studies were conducted for dietary noncompliance showing noncompliance rate from 87.5 to $58.9 \%$. This study shows that noncompliance to medication among T2DM patients was 69\%. Study in India performed by using same tool showed noncompliance varying from $55^{18}$ to $60 \% .{ }^{19}$ Medication noncompliance in a study done in eastern Uganda was $16.7 \%$ in Ethiopia ${ }^{20}$ and 28 to $31.2 \%$ in Kolkata, ${ }^{21,22}$ with other studies showing $42.3 \%$ in India, ${ }^{23} 50 \%$ in Spain, ${ }^{24} 54.5 \%$ in Kenya, ${ }^{25}$ and 67.9\% in Saudi Arabia. ${ }^{8}$

Table 2 Response on PDAQ

\begin{tabular}{|c|l|l|}
\hline & Questions & $\begin{array}{l}\text { Mean } \pm \text { SD, } \\
n=182\end{array}$ \\
\hline Q1. & $\begin{array}{l}\text { No. of days followed healthful eating } \\
\text { plan in past 7 days }\end{array}$ & $5.12 \pm 1.42$ \\
\hline Q2. & $\begin{array}{l}\text { No. of days ate adequate fruits and } \\
\text { vegetables in past 7 days }\end{array}$ & $5.27 \pm 1.34$ \\
\hline Q3. & $\begin{array}{l}\text { No. of days ate carbohydrate- } \\
\text { containing food with low glycemic } \\
\text { index in past 7 days }\end{array}$ & $4.28 \pm 1.95$ \\
\hline Q4. & $\begin{array}{l}\text { No. of days remove food high in } \\
\text { sugar in past 7 days }\end{array}$ & $6.11 \pm 1.38$ \\
\hline Q5. & $\begin{array}{l}\text { No. of days ate high-fiber food in } \\
\text { past 7 days }\end{array}$ & $4.36 \pm 2.26$ \\
\hline Q6. & $\begin{array}{l}\text { No. of days carbohydrates were } \\
\text { spaced evenly throughout the day in } \\
\text { past 7 days }\end{array}$ & $5.96 \pm 1.62$ \\
\hline Q7. & $\begin{array}{l}\text { No. of days ate fish or food high in } \\
\text { omega-3 fats in past 7 days }\end{array}$ & $0.66 \pm 1.22$ \\
\hline Q8. & $\begin{array}{l}\text { No. of days ate food that contained } \\
\text { or was prepared with canola, wal- } \\
\text { nut, in past 7 days }\end{array}$ & $1.79 \pm 1.99$ \\
\hline Q9. & $\begin{array}{l}\text { No. of days remove foods high in fat } \\
\text { in past 7 days }\end{array}$ & $5.711 \pm 0.61$ \\
\hline
\end{tabular}

Abbreviation: PDAQ, Perceived Dietary Adherence Questionnaire; SD, standard deviation.

Table 3 Participants' noncompliance status

\begin{tabular}{|l|l|l|l|}
\hline \multirow{2}{*}{ Variables } & Number (\%) & Number (\%) & Number (\%) $n=182$ \\
\cline { 2 - 4 } & High compliance & Medium compliance & Low compliance \\
\hline Medication advice & $56(30.8)$ & $75(41.2)$ & $51(28.0)$ \\
\hline Dietary advice & $16(8.8)$ & $144(79.1)$ & $22(12.1)$ \\
\hline
\end{tabular}

Medication compliance: Score 8 high compliance, 6-7 medium compliance, and < 6 low compliance. Dietary compliance: > 75\% high compliance score, $75-50 \%$ medium compliance, and $<50 \%$ low compliance. 
Table 4 Study participants' characteristics

\begin{tabular}{|c|c|c|c|c|c|c|c|c|c|}
\hline \multirow[t]{2}{*}{ Variables } & \multirow{2}{*}{$\begin{array}{l}\text { Number } \\
(\%)(n= \\
182)\end{array}$} & \multicolumn{4}{|l|}{ Medication } & \multicolumn{4}{|l|}{ Diet } \\
\hline & & $\begin{array}{l}\text { Compliant } \\
(n=56)\end{array}$ & $\begin{array}{l}\text { Noncompliant } \\
(n=126)\end{array}$ & $\begin{array}{l}\text { Odds } \\
\text { ratio }\end{array}$ & $\begin{array}{l}p- \\
\text { Value }\end{array}$ & $\begin{array}{l}\text { Compliant } \\
(n=16)\end{array}$ & $\begin{array}{l}\text { Noncompliant } \\
(n=166)\end{array}$ & $\begin{array}{l}\text { Odds } \\
\text { ratio }\end{array}$ & $\begin{array}{l}p- \\
\text { Value }\end{array}$ \\
\hline \multicolumn{10}{|l|}{ Health facility type } \\
\hline Public & $91(50.0)$ & $23(25.3)$ & $68(74.7)$ & 1.68 & 0.108 & $3(3.3)$ & $88(96.7)$ & 4.89 & \multirow[t]{2}{*}{0.009} \\
\hline Private & $91(50.0)$ & $33(36.3)$ & $58(63.7)$ & & & $13(14.3)$ & $78(85.7)$ & & \\
\hline \multicolumn{10}{|l|}{ Age } \\
\hline $17-60$ & $\begin{array}{l}128 \\
(70.3)\end{array}$ & $42(32.8)$ & $86(67.2)$ & 0.72 & 0.358 & $10(7.8)$ & $118(92.2)$ & 1.48 & \multirow[t]{2}{*}{0.473} \\
\hline$>60$ & $54(29.7)$ & $14(25.9)$ & $40(74.1)$ & & & $6(11.1)$ & $48(88.9)$ & & \\
\hline \multicolumn{10}{|l|}{ Sex } \\
\hline Male & $97(53.3)$ & $34(35.1)$ & $63(64.9)$ & 0.65 & 0.181 & $12(12.4)$ & $85(87.6)$ & 0.35 & \multirow[t]{2}{*}{0.68} \\
\hline Female & $85(46.7)$ & 22 (25.9) & $63(74.1)$ & & & $4(4.7)$ & $81(95.3)$ & & \\
\hline \multicolumn{10}{|c|}{ No. of year with diabetes mellitus (DM) } \\
\hline $0.5-5$ & $\begin{array}{l}104 \\
(57.1)\end{array}$ & $31(30.4)$ & $71(69.6)$ & 1.04 & 0.901 & $6(5.9)$ & $96(94.1)$ & 2.29 & \multirow[t]{2}{*}{0.118} \\
\hline$>5$ & 78 (42.9) & $25(31.3)$ & $55(68.7)$ & & & $10(12.5)$ & $70(87.5)$ & & \\
\hline \multicolumn{10}{|l|}{ Occupational status } \\
\hline Self-employed & $\begin{array}{l}153 \\
(84.1)\end{array}$ & $41(26.8)$ & $112(73.2)$ & 2.93 & 0.008 & $15(9.8)$ & $138(90.2)$ & 0.33 & \multirow[t]{2}{*}{0.268} \\
\hline Job holders & $29(15.9)$ & $15(51.7)$ & $14(48.3)$ & & & $1(3.4)$ & $28(96.6)$ & & \\
\hline \multicolumn{10}{|l|}{ Level of education } \\
\hline $\begin{array}{l}\text { Illiterate } \\
\text { (no formal } \\
\text { education) }\end{array}$ & $71(39.0)$ & $10(14.1)$ & $61(85.9)$ & 4.32 & 0.001 & $1(1.4)$ & $70(98.6)$ & 10.94 & \multirow[t]{2}{*}{0.005} \\
\hline $\begin{array}{l}\text { Literate (formal } \\
\text { education) }\end{array}$ & $\begin{array}{l}111 \\
(61.0)\end{array}$ & $46(41.4)$ & $65(58.6)$ & & & $15(13.5)$ & $96(86.5)$ & & \\
\hline \multicolumn{10}{|l|}{ Place of residence } \\
\hline $\begin{array}{l}\text { Village } \\
\text { municipality }\end{array}$ & $27(14.8)$ & $5(18.5)$ & $22(81.5)$ & 2.16 & 0.135 & $1(3.7)$ & $26(96.3)$ & 2.79 & \multirow[t]{2}{*}{0.312} \\
\hline $\begin{array}{l}\text { City/ } \\
\text { Municipality }\end{array}$ & $\begin{array}{l}155 \\
(85.2)\end{array}$ & $51(32.9)$ & $104(67.1)$ & & & $15(9.7)$ & $140(90.3)$ & & \\
\hline \multicolumn{10}{|l|}{ Marital status } \\
\hline Married & $\begin{array}{l}162 \\
(89.0)\end{array}$ & $48(29.6)$ & $114(70.4)$ & 1.58 & 0.441 & $15(9.3)$ & $147(90.7)$ & 0.52 & \multirow[t]{2}{*}{0.526} \\
\hline Others & $20(11.0)$ & $8(40)$ & $12(60)$ & & & $1(5.0)$ & $19(95.0)$ & & \\
\hline \multicolumn{10}{|c|}{ Family history of DM } \\
\hline No & $\begin{array}{l}117 \\
(64.3)\end{array}$ & $31(26.5)$ & $86(73.5)$ & 1.73 & 0.094 & $7(10.8)$ & $58(89.2)$ & 1.45 & \multirow[t]{2}{*}{0.482} \\
\hline Yes & $65(35.7)$ & $25(38.5)$ & $40(61.5)$ & & & $9(7.7)$ & $108(92.3)$ & & \\
\hline \multicolumn{10}{|l|}{ Additional problem } \\
\hline No & $70(38.5)$ & $27(38.6)$ & $43(61.4)$ & 0.56 & 0.071 & $9(8.0)$ & $103(92.0)$ & 0.79 & \multirow[t]{2}{*}{0.649} \\
\hline Yes & $\begin{array}{l}112 \\
(61.5)\end{array}$ & $29(25.9)$ & $83(74.1)$ & & & $7(10.0)$ & $63(90.0)$ & & \\
\hline \multicolumn{10}{|l|}{ Tobacco use } \\
\hline $\begin{array}{l}\text { Current } \\
\text { nonsmoker }\end{array}$ & $\begin{array}{l}155 \\
(85.16)\end{array}$ & $44(28.4)$ & 111 (71.6) & 2.02 & 0.095 & $15(9.7)$ & $140(90.3)$ & 0.36 & \multirow[t]{2}{*}{0.312} \\
\hline Current smoker & $27(14.8)$ & $12(44.4)$ & $15(55.6)$ & & & $1(3.7)$ & $26(96.3)$ & & \\
\hline
\end{tabular}


Table 4 (continued)

\begin{tabular}{|c|c|c|c|c|c|c|c|c|c|}
\hline \multirow[t]{2}{*}{ Variables } & \multirow{2}{*}{$\begin{array}{l}\text { Number } \\
(\%)(n= \\
182)\end{array}$} & \multicolumn{4}{|l|}{ Medication } & \multicolumn{4}{|l|}{ Diet } \\
\hline & & $\begin{array}{l}\text { Compliant } \\
(n=56)\end{array}$ & $\begin{array}{l}\text { Noncompliant } \\
(n=126)\end{array}$ & $\begin{array}{l}\text { Odds } \\
\text { ratio }\end{array}$ & $\begin{array}{l}p- \\
\text { Value }\end{array}$ & $\begin{array}{l}\text { Compliant } \\
(n=16)\end{array}$ & $\begin{array}{l}\text { Noncompliant } \\
(n=166)\end{array}$ & $\begin{array}{l}\text { Odds } \\
\text { ratio }\end{array}$ & $\begin{array}{l}p- \\
\text { Value }\end{array}$ \\
\hline Never smoker & $\begin{array}{l}109 \\
(59.89)\end{array}$ & $31(28.4)$ & $78(71.6)$ & 1.31 & 0.406 & $102(93.6)$ & $7(6.4)$ & 0.25 & 0.168 \\
\hline Ever smoker & $\begin{array}{l}73 \\
(40.11)\end{array}$ & $25(34.2)$ & $48(65.8)$ & & & $64(87.7)$ & $9(12.3)$ & & \\
\hline \multicolumn{10}{|c|}{ Alcohol consumption } \\
\hline $\begin{array}{l}\text { Current } \\
\text { nondrinkers }\end{array}$ & $\begin{array}{l}146 \\
(80.22)\end{array}$ & $44(30.1)$ & $102(69.9)$ & 1.16 & 0.710 & $13(8.9)$ & $133(91.1)$ & 0.93 & \multirow[t]{2}{*}{0.914} \\
\hline $\begin{array}{l}\text { Current } \\
\text { drinkers }\end{array}$ & $36(19.8)$ & $12(33.3)$ & $24(66.7)$ & & & $3(8.3)$ & $33(91.7)$ & & \\
\hline Never drinkers & $\begin{array}{l}107 \\
(58.79)\end{array}$ & $34(31.8)$ & $73(68.2)$ & 0.89 & 0.725 & $6(5.6)$ & $101(94.4)$ & 2.59 & \multirow[t]{2}{*}{0.070} \\
\hline Ever drinkers & $75(41.2)$ & $22(29.3)$ & $53(70.7)$ & & & $10(13.3)$ & $65(86.7)$ & & \\
\hline
\end{tabular}

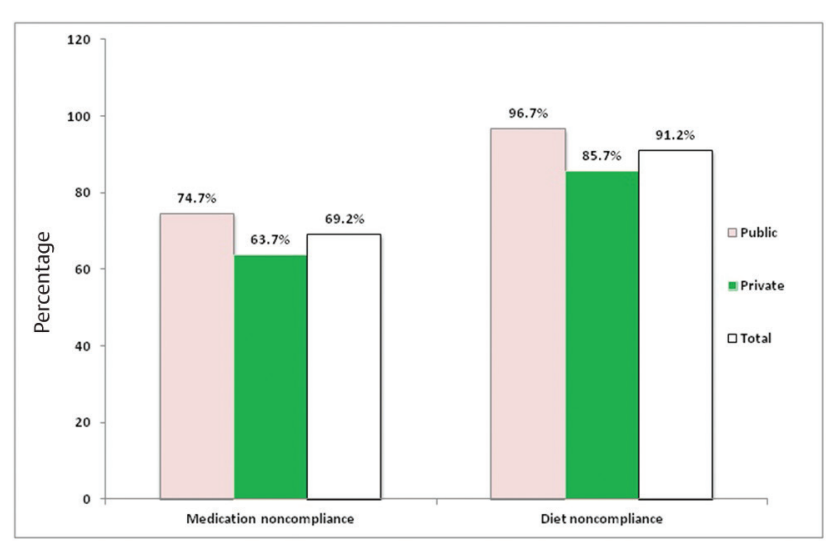

Fig. 1 Comparison of medication and diet noncompliance.

This difference in medication noncompliance between our and other studies is due to variation in categorization of the "degree of noncompliance." In our study only the score of $100 \%$ in MMAQ was considered as compliance to medication. In other studies, Adama (Gelaw et al) ${ }^{21}$ and south India (Divya and Nadig, Manobharathi et al $)^{18,19} \geq 75 \%$ were considered as compliance. Study of Uganda ${ }^{20}$ and Kolkata ${ }^{23}$ considered score $\geq 80 \%$ as compliance. Most of these studies, that is, studies of Ethiopia, ${ }^{22}$ Kenya, ${ }^{25}$ Adama, ${ }^{21}$ Kolkata, ${ }^{23}$ and South India ${ }^{18}$ covered data of single health care center. In this study there was a significant illiterate versus literate difference in noncompliance rate. Illiterate people were 4.32 times more likely to be noncompliant than literate $(p=0.001)$. Similar study in India showed that noncompliance to medication was significantly associated with educational status $(p=0.022)$ [23], $(p=0.04527) .{ }^{26}$ This study showed that self-employed participants were 2.93 times more likely to be noncompliant ( $p=0.008)$ than job holder participants, which can be correlated with similar study in tertiary care hospital in India, which showed that noncompliance to medication was significantly associated with employment status $(p=0.0001){ }^{26}$

Prevalence of dietary noncompliance in this study was 91.2\%. Other studies in Nepal showed noncompliance to diet from 41 [11] to $100 \%$ (medium + poor). ${ }^{10}$ International studies show dietary noncompliance variations from $97.8 \%$ in Egypt, ${ }^{27} 62 \%$ in Mexico, ${ }^{28} 48 \%$ in eastern Washington, ${ }^{29}$ to $37 \%$ in Botswana, South Africa. ${ }^{30}$ This study found that illiterate participants were 10.94 times more likely to be noncompliant to diet than literate. Participants who visited public hospital were 4.89 times more likely to be noncompliant to diet than those who visited private hospital/diabetes clinic. No similar study was conducted previously for comparison.

\section{Limitation of the Study}

In 7 days recall method, sometimes there could be recall bias. However, it is the most suitable method comparatively.

\section{Conclusion}

High rate of noncompliance to medication advice and dietary advice was found among T2DM patients in Kathmandu, Nepal. Dietary noncompliance was higher than medication noncompliance. It was found that place of treatment had significant effect on patients' dietary compliance. Medication noncompliance was affected by the participants' education and occupation status. Dietary noncompliance was influenced by level of education and place of treatment. Health care providers should be aware of such high prevalence of noncompliance in patients and put more efforts in educating patients regarding the necessity of compliance and poor outcomes that come from being noncompliant (with more focus in public hospitals). Further studies should be performed to find out more specifics on the determinants of noncompliance, which would help in intervention strategy.

\section{Ethics Approval and Consent to Participate}

Ethical approval was taken from National Health Research Council (NHRC). Permissions were taken from Teaching Hospital, Bir Hospital, Metro Hospital, Diabetes Thyroid \& Endocrinology Care Center, and Sahid Gangalal National Heart Center, before data collection. 


\section{Funding}

None.

\section{Conflict of Interest}

None.

\section{Acknowledgments}

We would like to offer especial thanks to all the participants who are actively involved in this research and to all the hospitals that allowed and provided friendly environment for data collection. We are grateful to the Department of Community Medicine and Public Health (IOM) for providing opportunity to carry out the research.

\section{References}

1 American Diabetes Association. Diagnosis and classification of diabetes mellitus. Diabetes Care 2010;33(1 Suppl 1):S62-S69

2 Diabetes. Chronic Disease Prevention and Health Promotion. 2018. Available at: https://www.cdc.gov/chronicdisease/ resources/publications/aag/diabetes.htm. Accessed April 7, 2018

3 Sackett DL, Haynes RB, Gibson ES, et al. Randomised clinical trial of strategies for improving medication compliance in primary hypertension. Lancet 1975;1(7918):1205-1207

4 The top 10 causes of death. 2018. Available at: http://www. who.int/mediacentre/factsheets/fs310/en/. Accessed April 7 2018

5 Diabetes Atlas IDF 2018. Available at: https://www.idf.org/elibrary/epidemiology-research/diabetes-atlas/134-idf-diabetes-atlas-8th-edition.html. Accessed April 72018

6 Diabetes Atlas IDF. 8th edition 2017 Country Reports-Nepal. 2018. Available at: http://reports.instantatlas.com/report/ view/846e76122b5f476fa6ef09471965aedd/NPL?clear=true. Accessed April 72018

7 Bhandari GP, Angdembe MR, Dhimal M, Neupane S, Bhusal C. State of non-communicable diseases in Nepal. BMC Public Health 2014;14(1):23

8 Khan AR, Al-Abdul Lateef ZN, Al Aithan MA, Bu-Khamseen MA, Al Ibrahim I, Khan SA. Factors contributing to non-compliance among diabetics attending primary health centers in the Al Hasa district of Saudi Arabia. J Family Community Med 2012;19(1):26-32

9 Poudel RR. Diabetes and endocrinology in Nepal. Indian J Endocrinol Metab 2014;18(1):118-119

10 Parajuli J, Saleh F, Thapa N, Ali L. Factors associated with nonadherence to diet and physical activity among Nepalese type 2 diabetes patients; a cross sectional study. BMC Res Notes 2014;7(1):758

11 Ghimire S. Barriers to diet and exercise among Nepalese type 2 diabetic patients. Int Sch Res Notices 2017;2017:1273084

12 Maddigan SL, Majumdar SR, Toth EL, Feeny DH, Johnson JA; DOVE Investigators. Health-related quality of life deficits associated with varying degrees of disease severity in type 2 diabetes. Health Qual Life Outcomes 2003;1(1):78

13 Anderson JW, Gustafson NJ. Adherence to high-carbohydrate, high-fiber diets. Diabetes Educ 1989;15(5):429-434

14 Okello S, Nasasira B, Muiru ANW, Muyingo A. Validity and reliability of a self-reported measure of antihypertensive medication adherence in Uganda. PLoS One 2016;11(7):e0158499

15 Lee WY, Ahn J, Kim JH, et al. Reliability and validity of a self-reported measure of medication adherence in patients with type 2 diabetes mellitus in Korea. J Int Med Res 2013;41(4):1098-1110

16 Asaad G, Sadegian M, Lau R, et al. The reliability and validity of the perceived dietary adherence questionnaire for people with type 2 diabetes. Nutrients 2015;7(7):5484-5496

17 WHO STEPS Instrument. World Health Organization. 2018. Available at: http://www.who.int/chp/steps/STEPS_Instrument_v2.1.pdf. Accessed April 7, 2018

18 Divya S, Nadig P. Factors contributing to non-adherence to medication among type 2 diabetes mellitus in patients attending tertiary care hospital in south India. Asian J Pharm Clin Res 2015;8(2):274-276

19 Manobharathi M, Kalyani P, Arulmani A. Factors associated with therapeutic non-compliance among type 2 diabetes mellitus patients in Chidambaram, Tamilnadu, India. Int J Community Med Public Health 2017;4(3):787-791

20 Bagonza J, Rutebemberwa E, Bazeyo W. Adherence to anti diabetic medication among patients with diabetes in eastern Uganda; a cross sectional study. BMC Health Serv Res 2015;15(1):168

21 Gelaw BK, Mohammed A, Tegegne GT, et al. Nonadherence and contributing factors among ambulatory patients with antidiabetic medications in Adama Referral Hospital. J Diabetes Res 2014;2014:617041

22 Kassahun A, Gashe F, Mulisa E, Rike WA. Nonadherence and factors affecting adherence of diabetic patients to anti-diabetic medication in Assela General Hospital, Oromia Region, Ethiopia. J Pharm Bioallied Sci 2016;8(2):124-129

23 Mukherjee S, Sharmasarkar B, Das KK, Bhattacharyya A, Deb A. Compliance to anti-diabetic drugs: observations from the diabetic clinic of a medical college in Kolkata, India. J Clin Diagn Res 2013;7(4):661-665

24 García-Pérez LE, Álvarez M, Dilla T, Gil-Guillén V, Orozco-Beltrán $\mathrm{D}$. Adherence to therapies in patients with type 2 diabetes. Diabetes Ther 2013;4(2):175-194

25 Waari G, Mutai J, Gikunju J. Medication adherence and factors associated with poor adherence among type 2 diabetes mellitus patients on follow-up at Kenyatta National Hospital, Kenya. Pan Afr Med J 2018;29:82

26 Kavitha S, Nalini GK, Suresh RM, Sahana GN, Deepak P, Nagaral JV. Treatment adherence and factors contributing to non adherence among type 2 diabetes mellitus patients in a tertiary care hospital: a cross sectional study. Int J Basic Clin Pharmacol 2017;6(3):689-694

27 Ibrahim NK, Attia SG, Sallam SA, Fetohy EM, El-Sewi F. Physicians' therapeutic practice and compliance of diabetic patients attending rural primary health care units in Alexandria. J Family Community Med 2010;17(3):121-128

28 Hernández-Ronquillo L, Téllez-Zenteno JF, Garduño-Espinosa J, González-Acevez E. Factors associated with therapy noncompliance in type-2 diabetes patients. Salud Publica Mex 2003;45(3):191-197

29 Shultz JA, Sprague MA, Branen LJ, Lambeth S. A comparison of views of individuals with type 2 diabetes mellitus and diabetes educators about barriers to diet and exercise. J Health Commun 2001;6(2):99-115

30 Ganiyu AB, Mabuza LH, Malete NH, Govender I, Ogunbanjo GA. Non-adherence to diet and exercise recommendations amongst patients with type 2 diabetes mellitus attending Extension II Clinic in Botswana. Afr J Prim Health Care Fam Med 2013;5(1):457 